\title{
COMPARISON OF High FEED MACHINING WITH CONVENTIONAL MiLling IN TERMS OF SURFACEQUALiTY AND PRODUCTIVITY
}

\author{
Marcel Kuruc*, Marek Vozár, Vladimír Šimna, Tomáš Vopát, \\ Jana Moravčíková \& Jozef Peterka
}
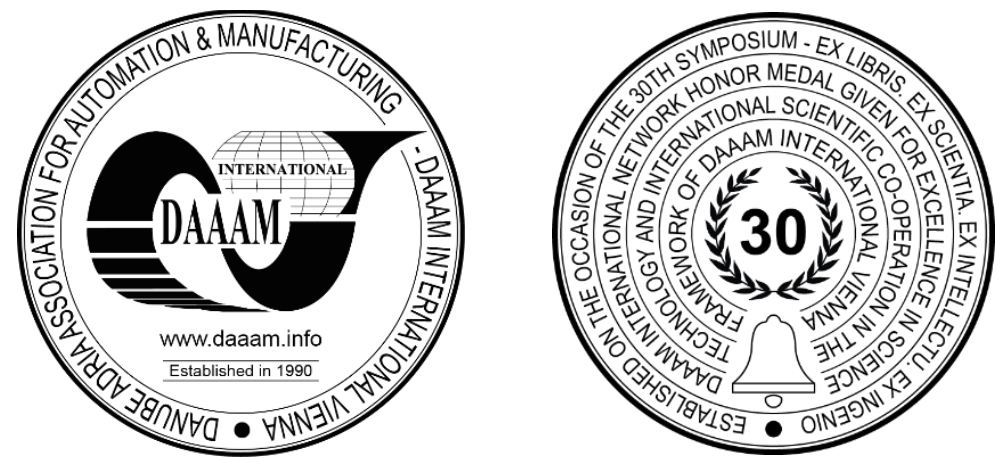

This Publication has to be referred as: Kuruc, M[arcel]; Vozar, M[arek]; Simna, V[ladimir]; Vopat, T[omas]; Moravcikova, J[ana] \& Peterka, J[ozef] (2019). Comparison of High Feed Machining with Conventional Milling in Terms of Surface Quality and Productivity, Proceedings of the 30th DAAAM International Symposium, pp.0376-0383, B. Katalinic (Ed.), Published by DAAAM International, ISBN 978-3-902734-22-8, ISSN 1726-9679, Vienna, Austria DOI: $10.2507 / 30$ th.daaam.proceedings.051

\begin{abstract}
Many industrial corporations are trying to increase productivity. They were made many types of research focused on cost-effective productivity increasing. Researchers and engineers were created new machining strategies and advanced processes, which could be enhanced by modified geometry, advanced coatings and new cutting materials. One of the costeffective methods to increase productivity is High Feed Machining (HFM). This method does not require any special equipment, such as high-speed spindle. Moreover, it does not require any special conditions neither. Due to the fast rapid traverse of many modern machine tools, High Feed Machining can be performed on most of them. This article compares machining of the reference steel materials - C45 by conventional milling and High Feed Machining. The experiment is based on the creating of some simple shapes, such as vertical and horizontal surfaces, notches, cylinders, etc. There were measured several surface roughness parameters. Results of the experiment could be applied to determine what advantages High Feed Machining brings and when it is advantageous.
\end{abstract}

Keywords: High feed machining; Surface quality; Productivity; Reference steel; Advanced machining.

\section{Introduction}

High feed machining (HFM) is known as a cost-effective roughing strategy due to higher material removal rate in contrast with conventional milling. The surface roughness is increasing with higher feed as well [1]. This effect can be partially reduced by using advanced tool geometry (Fig. 1). HFM is using very high values of feed rate (approx. 10 times higher). High feed alone could cause a significant increase in cutting force [2]. Therefore, the depth of cut (DOC) is decreased in HFM, along with the decreased lead angle of the milling tool. It affects the section of the layer of cut resulting in the change of direction of cutting force towards the spindle, so the cutting force is directed positively - it causes reducing of vibrations and decreasing of machine load during the machining process. It also affects the chip formation during the machining process - it causes a lower width of the chip than the feed per tooth. This mechanism is known as "chip 
thinning" [3], [4]. To reach the correct feed per tooth, high enough feed rate is needed. Fortunately, many modern machine tools offer the highest value of feed rate equals to rapid traverse rate, which should be enough for most high feed applications. Milling tools for high feed machining are produced in different forms and dimensions, such as inserts or solid end mills (Fig. 2) [5], [8], [9].

The geometry of the cutting part of tools for high speed machining is different from the tools used for conventional milling, and this could cause different surface quality when surfaces and features of the workpiece are machined. An evaluation of how the high feed machining will impact the surface quality of the machined component in comparison with the conventional machining method, and which method of machining provide better surface should be made. The possibility of using high feed machining not only just for roughing operations but also for finishing could increase the productivity of this method even more in certain cases [6].

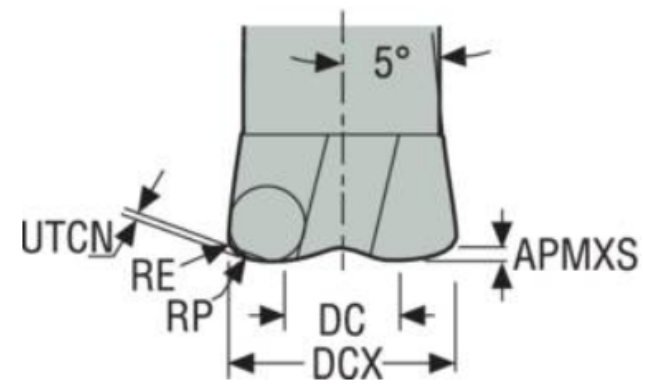

$\begin{array}{ll}\text { APMXS } & \text { Depth of cut maximum in feed direction side } \\ \text { DC } & \text { Cutting diameter } \\ \text { DCX } & \text { Maximum cutting diameter } \\ \text { RE } & \text { Radius } \\ \text { RP } & \text { Programmed radius } \\ \text { UTCN } & \text { Uncut thickness }\end{array}$

Fig. 1. Geometry of high feed end mill [7]
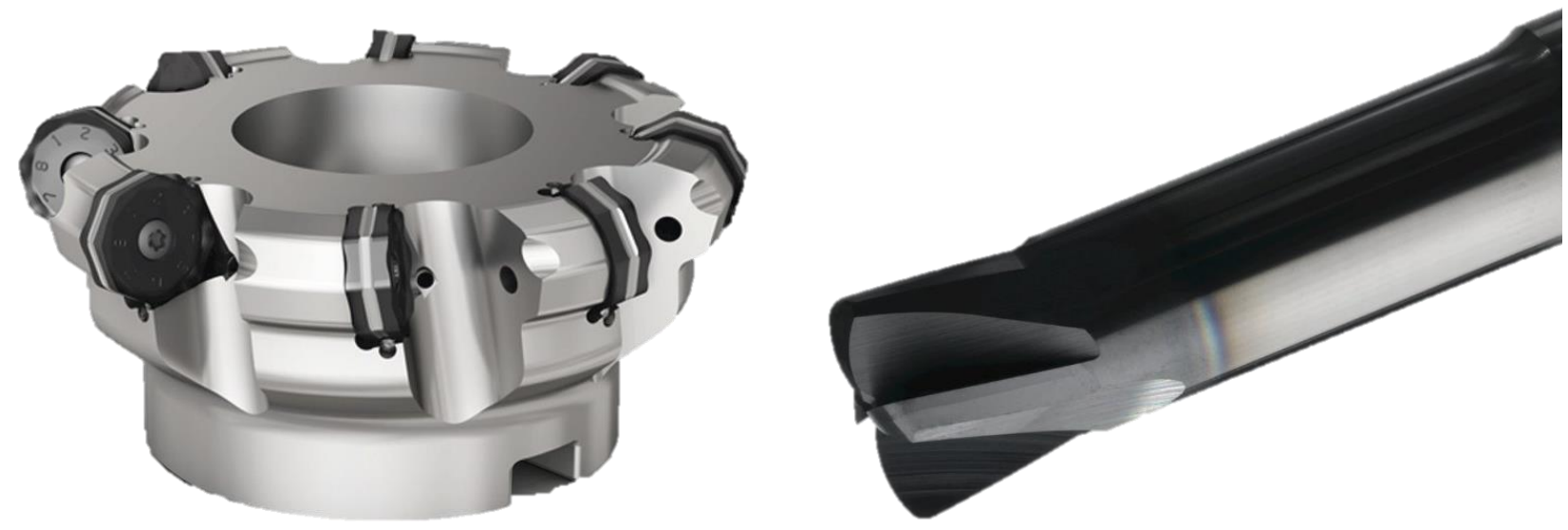

Fig. 2. Cutting tools for high feed machining [8], [9]

The main advantage of high feed machining is productivity. It is reached by a higher increase in feed than a decrease in depth of cut (DOC). Lower DOC also causes material additament more uniform, therefore there is often no need for semi-finishing, which will decrease machining time even more. However, fast feed rate demands fast enough control system, otherwise pauses to read some lines of NC program in advance will be needed [10], [11], [12], [13]. The aim of the experiment is to determine surface quality after HFM and if finishing is necessary in all cases after this process.

\section{Machining method Machining method}

In the experiment, a machine tool for high speed cutting (HSC) and high feed machining (HFM) was used. This machine tool is using high-speed spindle (it can use spindle speed up to 42,000 rpm). During HSC process, chips drain most of the generated heat. It causes the workpiece material strength reduction in the cutting zone. It also causes cutting force reduction and allows to machine hardened steels. The machine tool has linear drives due to the increase in precision. These linear drives allow applying feed rate (and rapid traverse) up to $40 \mathrm{~m} / \mathrm{min}$. Such a high value of feed rate can be applied in high feed machining (HFM). Combination of high speed cutting (HSM) and high feed machining (HFM) is often labelled as high speed machining (HSM). 
High speed milling machine DMG Mori HSC 105 linear (Fig. 3) was used in the experiment. This machine tool can operate continuously in five axes. It can operate as a conventional milling machine, high speed cutting machine, and high feed milling machine. Therefore, it suits to this research, as well as further possible experiments [14].

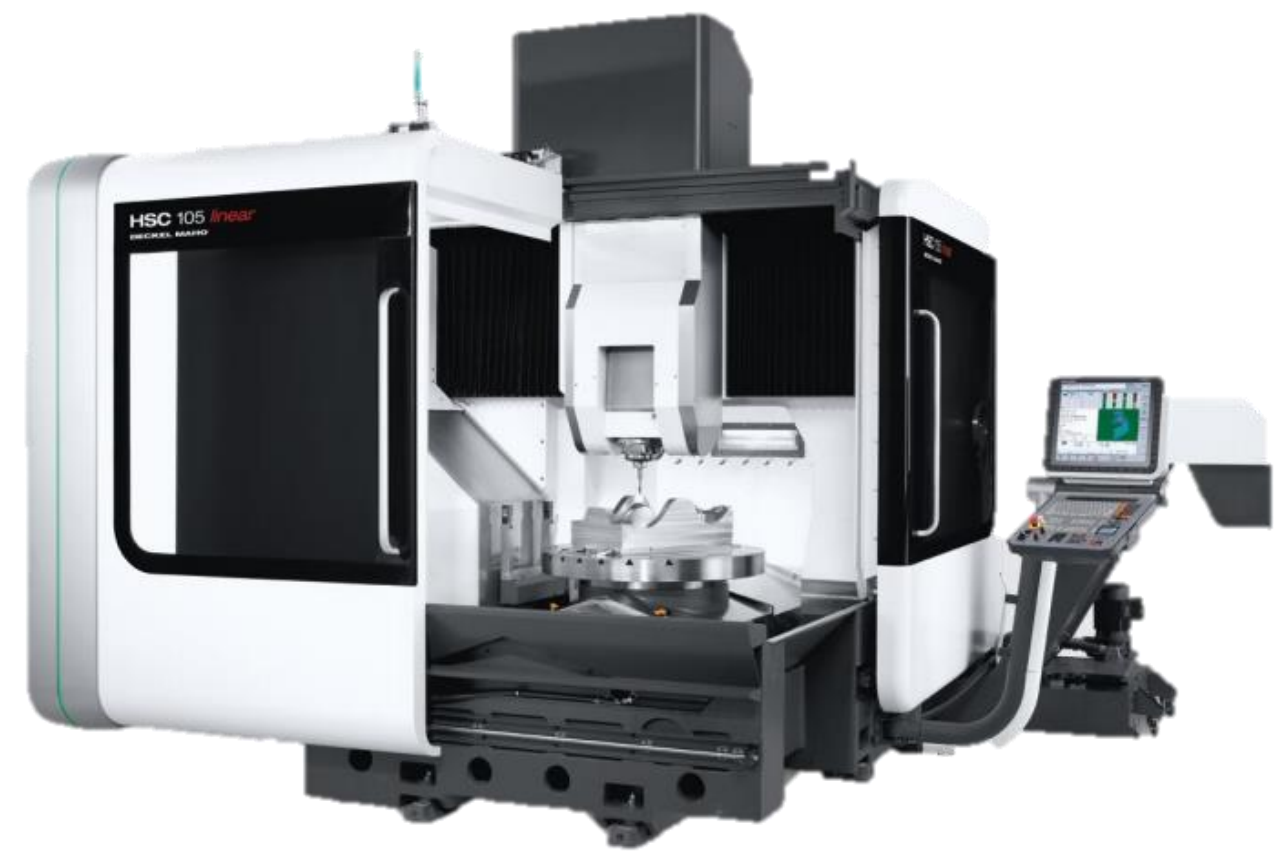

Fig. 3. High speed machine tool DMG Mori HSC 105 linear [14]

Milling tool for general purpose JS 553 and high feed milling tool JHF 980 were used as a cutting tool (Fig. 4). Seco Tools Company manufactured both tools. They both have: cutting diameter $10 \mathrm{~mm}$, and contain 3 flutes. Their parameters and dimensions are in Table 1. The material categories recommended to be machined by these tools are shown in Table 2. In CAD software Autodesk PowerShape Ultimate 2018 was created a 3D model of the workpiece. Then a CAD model was imported into CAM software Autodesk PowerMill Ultimate 2018, where CL data for conventional machining strategies and CL data for HFM machining strategies were generated. After verification of the tool paths via simulation, NC program for control system Heidenhain iTNC 530 was generated via proper postprocessor. Reference steel material C45 (class of machinability - P4) was used as workpiece material.
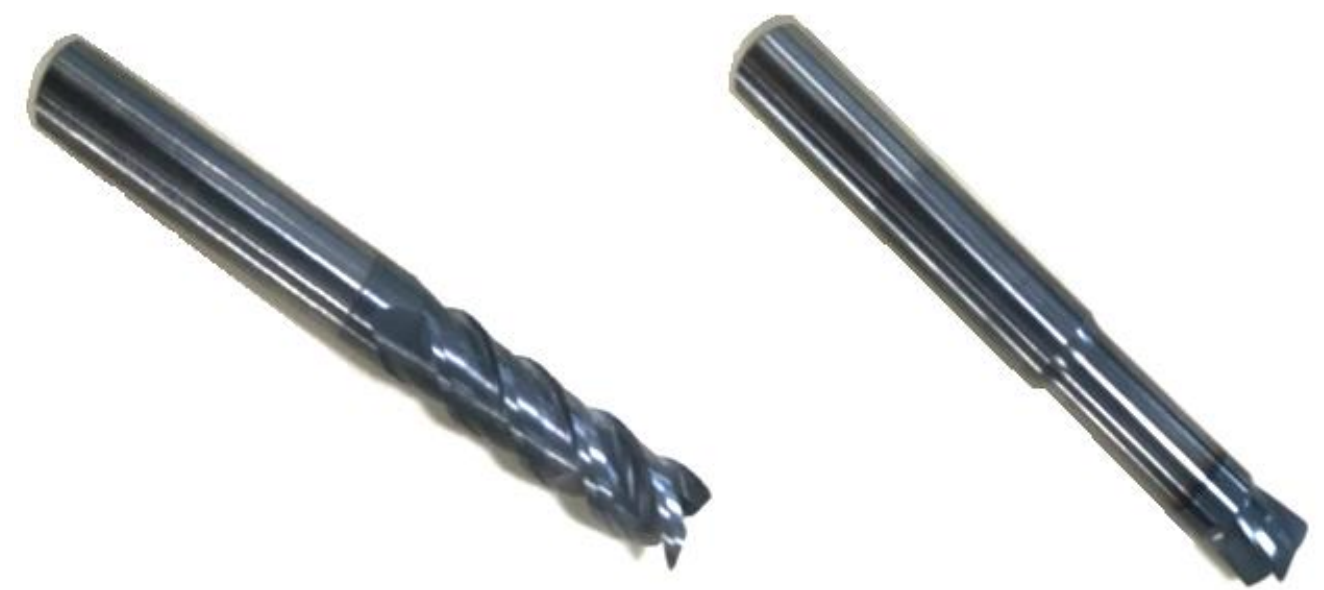

Fig. 4. Milling tools JS 553 (left) and JHF 980 (right) from Seco Tools Company

\begin{tabular}{|c|c|c|c|c|}
\hline Milling cutter & $\begin{array}{c}\text { Diameter } \\
{[\mathbf{m m}]}\end{array}$ & $\begin{array}{c}\text { Number of teeth } \\
{[-]}\end{array}$ & $\begin{array}{c}\text { Maximum DOC } \\
{[\mathbf{m m}]}\end{array}$ & $\begin{array}{c}\text { Overall length } \\
{[\mathbf{m m}]}\end{array}$ \\
\hline JS 553 & 10 & 3 & 35 & 85 \\
\hline JHF 980 & 10 & 3 & 0.5 & 80 \\
\hline
\end{tabular}

Table 1. Main dimensions of milling tools [15] 


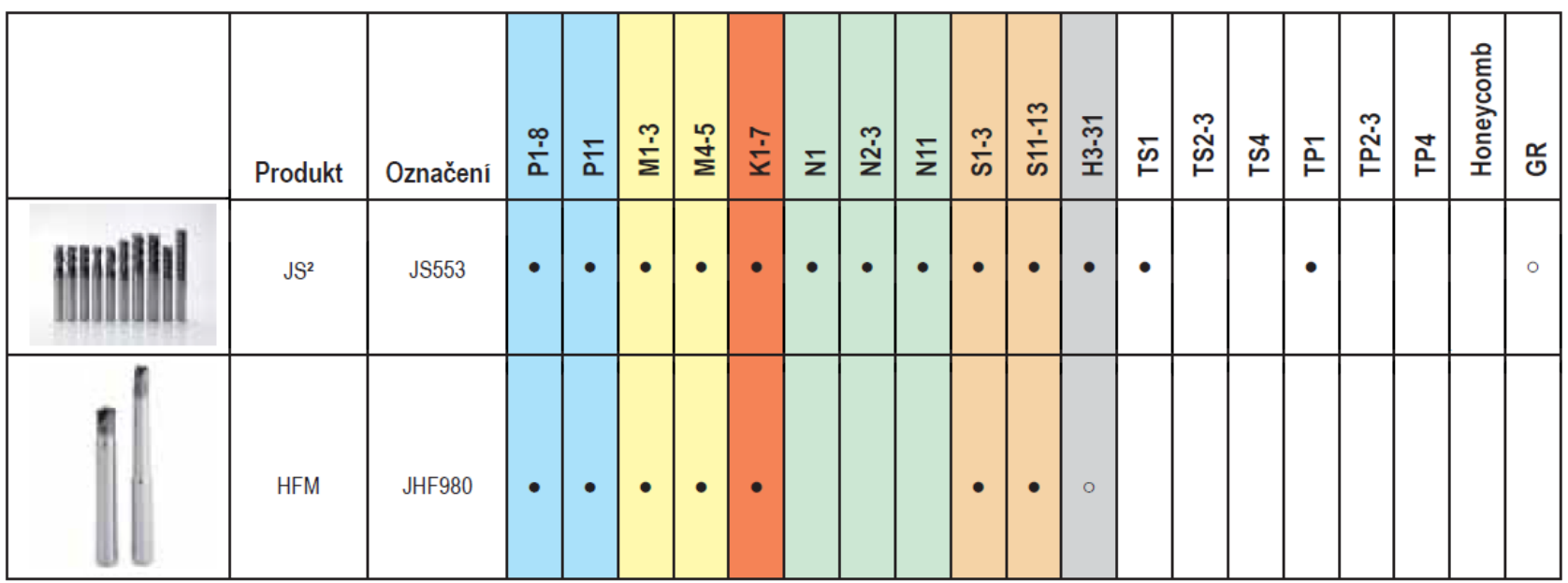

Table 2. Cutting tool applications according workpiece material [15]

\section{Description of the experiment}

The reference material for steels - C45 was used as a workpiece. This workpiece has dimensions 100x100x50 mm (two pieces). C45 is medium carbon steel with hardness $250 \mathrm{HB}$, yield strength $400 \mathrm{MPa}$, tensile strength $700 \mathrm{MPa}$ and fracture elongation $16 \%$ [15]. Its chemical composition is recorded in Table 3. The first workpiece was machined by conventional milling method, and the second workpiece was machined by HFM method. Several different features were designed on the workpiece to determine the behaviour of HFM at different surfaces, as shown in Fig. 5.

\begin{tabular}{|c|c|c|c|c|c|c|c|c|c|}
\hline element & $\mathbf{C}$ & $\mathbf{S i}$ & $\mathbf{M n}$ & $\mathbf{P}$ & $\mathbf{S}$ & $\mathbf{C r}$ & $\mathbf{M o}$ & $\mathbf{N i}$ & $\mathbf{F e}$ \\
\hline wt. \% & 0.46 & 0.4 & 0.65 & 0.045 & 0.045 & 0.2 & 0.03 & 0.4 & bal. \\
\hline
\end{tabular}

Table 3. Chemical composition of C45 steel material [16]

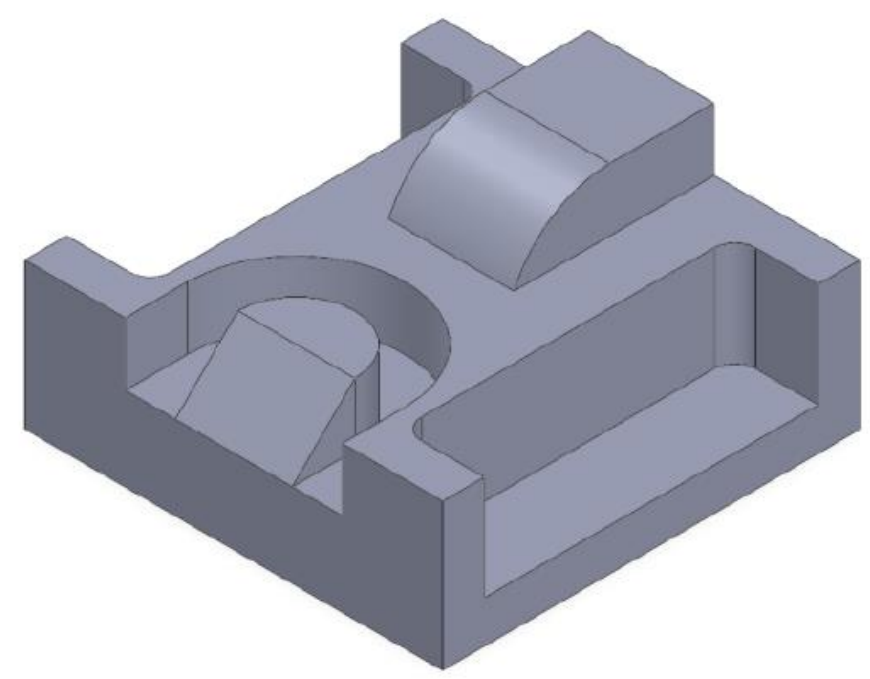

Fig. 5. Model of the part with different features

For each method of machining were set different cutting parameters - recommended conditions by tool manufacturer for the specific machining method. It means, in the experiment was compared conventional milling $(\mathrm{CM})$ with the proper tool for CM and proper cutting parameters for CM, with high feed machining (HFM) with the proper tool for HFM and proper cutting parameters for HFM. These conditions were chosen because using a tool for HFM under cutting condition for $\mathrm{CM}$ could not be considered as proper representant of conventional machining. Even when the cutting condition for HSM with just a fragment of recommended feed will be used, it could not be considered as proper representant of conventional machining, as well. Actual cutting parameters used in the experiment are shown in Table 4. 


\begin{tabular}{|c|c|c|c|c|c|c|}
\hline $\begin{array}{c}\text { Milling } \\
\text { method }\end{array}$ & $\begin{array}{c}\text { Cutting speed } \\
{\left[\mathbf{m}_{\left.\mathbf{m} \mathbf{m i n}^{-1}\right]}\right.}\end{array}$ & $\begin{array}{c}\text { Spindle speed } \\
{[\mathrm{rpm}]}\end{array}$ & $\begin{array}{c}\text { Feed rate } \\
{\left[\mathrm{mm} \cdot \mathbf{m i n}^{-1}\right]}\end{array}$ & $\begin{array}{c}\text { Feed per tooth } \\
{[\mathbf{m m}]}\end{array}$ & $\begin{array}{c}\text { Infeed } \\
{[\mathbf{m m}]}\end{array}$ & $\begin{array}{c}\text { Depth of cut } \\
{[\mathbf{m m}]}\end{array}$ \\
\hline CM & 130 & 4138 & 870 & 0.07 & 10 & 1 \\
\hline HFM & 250 & 7958 & 7162 & 0.3 & 5 & 0.25 \\
\hline
\end{tabular}

Table 4. Machining parameters used in experiment [15]

Cutting parameters and conditions, which were not labelled in Table 4, were constant (such as $0.5 \mathrm{~mm}$ material additament and blast air as coolant). However, because the design of the tool for HFM does not allow to use the proper depth of cut, vertical faces were not finished by HFM. These faces were only roughed without material additament in the radial direction [5]. An additional controlled axis was used during machining of chamfer and upper fillet on the workpiece.

Machining time and surface quality were compared after machining. A standard stopwatch was used to measuring of the machining time. The surface quality was measured by Zeiss Surfcom 5000 contour and surface measuring machine. Evaluated were surface roughness parameters Ra, Rz, Rt, Rp and Rv. This device is shown in Fig. 6.

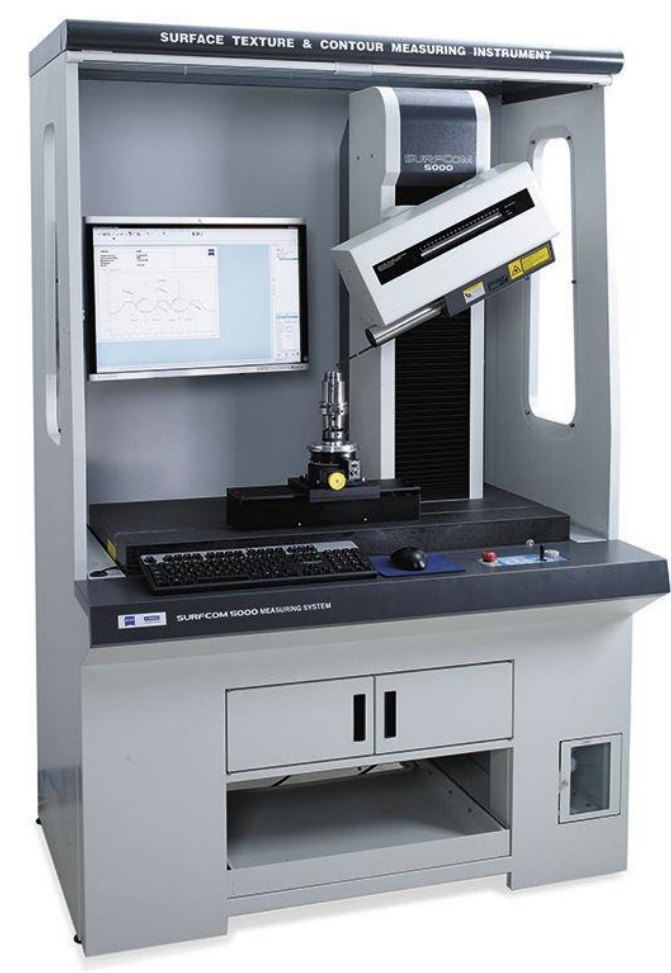

Fig. 6. Zeiss Surfcom 5000 surface texture \& contour measuring instrument

Zeiss Surfcom 5000 is an accurate and fast measuring device with a universal body to make all surface measurements easier to operate with. This measures more surfaces in just one step while making it more effective. It is particularly for the auto and mechanical engineering fields. This device was designed for measure and engineer lenses, bearings and spindles with accurate levels of around 0.31 nanometers on average. It also uses five lasers on its interferometer to measure. The device also has a $\mathrm{T}$ stylus and a ratio of the measuring range to the resolution of approximately 42 million to 1 [17].

\section{Results of the experiment}

During the experiment were made two experimental samples. The first sample was machined by conventional milling (CM) and the second one was machined by high feed machining (HFM). There were used above-mentioned cutting conditions. There were measured surface roughness in several places. There are recorded only some of the results due to their high amount. The results are recorded in Table 5. There was added a figure with the selected area to prevent the misunderstanding of the position labelling of measurement. The measurement recorded in the table was provided by Zeiss Surfcom 5000 contour and surface measuring machine. Value of each surface roughness parameter is the average value of five measuring. 


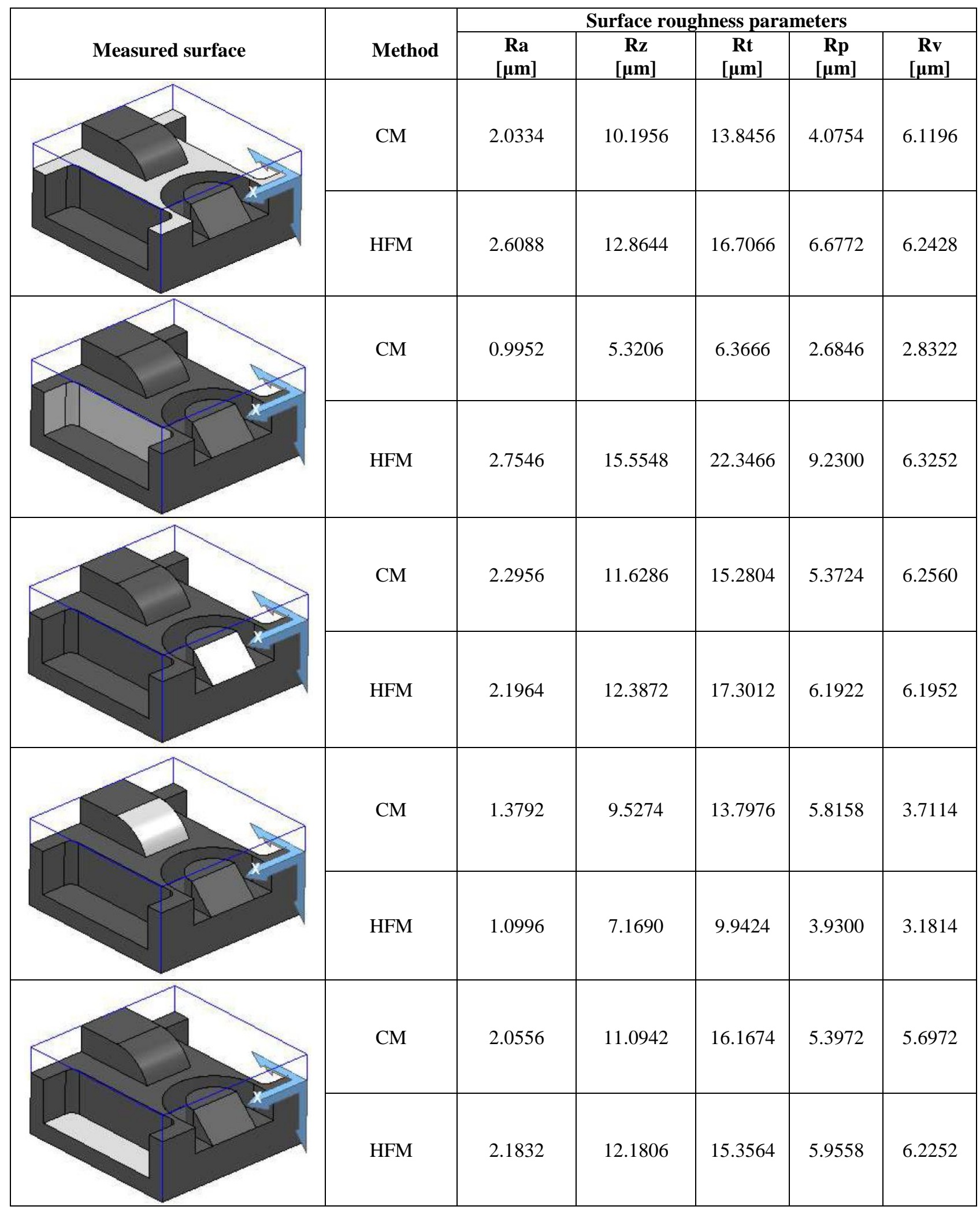

Table 5. Selected results of the measurement

Considering the principle and application of HFM, there were expected much worse surface quality for this method of machining in comparison with conventional machining. According to results recorded in Table 5, there can be seen that the worst results for HFM were obtained at measuring surface roughness at the vertical area (Ra increased by 177 $\%$ ). It could be caused by machining without finishing - during roughing of these faces were not leaving any radial material additament (due to milling tool geometry). However, there were not observed a big difference in surface quality between those methods on the other surfaces. On horizontal areas, there was increased surface roughness parameter Ra by $28 \%$ in the middle area and $6 \%$ in the bottom of the grooves. 
However, in some cases were achieved better surface roughness after HFM - there was observed a reduction of surface roughness parameter Ra by $4 \%$ on the sloping surface and by $20 \%$ on the rounded surface. It could be caused by more uniform material additament.

The main advantage of high feed machining is a reduction of the machining time. In Table 6 is shown real machining time for conventional milling and HFM. Using of HFM can substitute semi-finishing as well, however, in the experiment, it was not used (not even for conventional machining). Both machining methods could be divided into roughing and finishing. However, for both machining methods were used their own preferred machining strategies. According to machined features, there were used for each machining method several different roughing strategies, as well as several finishing strategies. However, they are summarized into their own categories in Table 6.

\begin{tabular}{|c|c|c|c|}
\hline Method & $\begin{array}{c}\text { Roughing } \\
{[\mathrm{min}]}\end{array}$ & $\begin{array}{c}\text { Finishing } \\
{[\mathrm{min}]}\end{array}$ & $\begin{array}{c}\text { Machining time } \\
{[\mathrm{min}]}\end{array}$ \\
\hline CM & 74.00 & 16.33 & 90.33 \\
\hline HFM & 61.92 & 3.75 & 65.67 \\
\hline
\end{tabular}

Table 6. Machining time of conventional machining and HFM

High feed machining can provide time reduction in both roughing and finishing, as can be seen in Table 6 . Total machining time of conventional machining is higher approximately by $38 \%$ (20\% higher for roughing, $335 \%$ for finishing). If there were used semi-finishing, total machining time of conventional machining would be even higher. Conventional machining was using double infeed $(10 \mathrm{~mm})$ and quadruple depth of cut $(1 \mathrm{~mm})$, while HFM was using over four times higher feed per tooth $(0.3 \mathrm{~mm})$. However, HFM works at almost double cutting speed $(250 \mathrm{~m} / \mathrm{min})$ and therefore the resultant feed rate was over eight times higher $(7162 \mathrm{~mm} / \mathrm{min})$. Specific conditions of HFM allow using some machining strategies, which are not suitable for conventional machining. However, much bigger milling cutters with inserts are usually used for HFM in terms of roughing, which can provide even higher time reduction. For HFM, using of infeed with a value of half of the tool diameter is necessary due to the specific design of solid end mills. If there were compared tools according to the same infeed instead of the same shrink diameter, results of HFM could be even better [18].

\section{Conclusion}

According to obtained results, we can confirm that high feed machining (HFM) can reach machining time reduction and therefore it is proper for roughing. HFM allowed using higher feeds per tooth, as well as higher cutting speeds due to the specific design of the cutting tools. However, this specific design also prevents the usage of higher infeed and depths of cut. The specific design of the tools creates relatively low surface roughness of the machined workpiece. Therefore, despite the high difference in feed, its value is comparable with surface roughness after conventional milling. Even dimensional accuracy between those two methods is similar. After roughing by conventional milling, obvious steps remain on the workpiece. In some cases, there would be needed to use also semi-finishing. On the other hand, after roughing by HFM, the workpiece does not demand additional semi-finishing.

Obtained surface roughness measurements show that better surface roughness is achieved after conventional milling in most of the cases. However, the difference in the surface roughness between HFM and conventional machining is low. HFM achieved even better results than conventional machining in some cases. Therefore, HFM could be applied even for finishing, if standard surface roughness is sufficient. However, HFM is not very suitable for finishing of vertical surfaces, because of the specific design of the tool - these surfaces cannot be satisfactorily finished by HFM, and therefore there is achieved higher surface roughness $(2.8 \mu \mathrm{m})$.

Results of application of the advanced tool design could be applied in the cutting edge preparation. Further research will be focused on the determination of the cutting edge difference between advanced tool design for enhancement of the cutting edge preparation; as well as the determination of the influence of high speed cutting (HSC) on the machining process and its comparison with HFM and conventional machining.

\section{Acknowledgments}

The article was written with the support of the Project of VEGA grant agency of the Ministry of Education, Science, Research and Sport of the Slovak Republic and the Slovak Academy of Sciences, no. 1/0097/17: "The research of a novel method for cutting edge preparation to increase tool performance in the machining of difficult-to-machine materials".

This work was supported by the Slovak Research and Development Agency under the Contract no. APVV-16-0057“ Research into the Unique Method for Treatment of Cutting Edge Microgeometry by Plasma Discharges in Electrolyte to Increase the Tool Life of Cutting Tools in Machining Difficult-to-Machine Materials. 


\section{References}

[1] Zauskova, L.; Czan, A.; Sajgalik, M.; Drbul, M. \& Rysava, Z. (2017). Triaxial measurement of residual stress after high feed milling using x-ray diffraction, TRANSCOM 2017, Procedia Engineering 192 (2017), pp. 982 - 987.

[2] Begic-Hajdarevic, D.; Cekic, A. \& Kulenovic, M. (2014). Experimental Study on the High Speed Machining of Hardened Steel, Proceedings of the 24th International DAAAM Symposium, Published by DAAAM International, Vienna, 2014, Procedia Engineering 69 (2014) 291 - 295.

[3] Hense, R.; Wels, Ch.; Kersting, P.; Vierzigmann, U.; Löffler, M.; Biermann, D. \& Merklein M. (2014). High-feed milling of tailored surfaces for sheet-bulk metal forming tools, German Academic Society for Production Engineering (WGP) 2014, In: Prod. Eng. Res. Devel. (2015) vol. 9, pp. 215-223.

[4] Lucas, H.; Denkena, B.; Grove, T.; Krebs, E.; Kersting, P.; Freiburg, D. \& Biermann, D. (2015). Analysis of Residual Stress States of Structured Surfaces Manufactured by High-Feed and Micromilling. HTM Journal of Heat Treatment and Materials: Vol. 70, No. 4, pp. 183-189.

[5] Schultz, H. \& Hock, S. (1995). High-speed Milling of Dies and Moulds - Cutting Conditions and Technology, Technical University of Darmstadt, Germany.

[6] Coelho, R.; Fagali de Souza, A.; Roger, A.; Rigatti, A. \& Ribeiro, A. (2009). Mechanistic approach to predict real machining time for milling free-form geometries applying high feed rate, Springer-Verlag London Limited 2009, In: International Journal of Advanced Manufacturing Technology (2010) vol. 46, pp. 1103-1111.

[7] SECO Tools. High Feed Machining Solid Carbide End Mills. Available from: https://www.secotools.com/\#article/m_7472. Accessed: 2019-01-25.

[8] SECO Tools. HFM. Available from: https://www.secotools.com/\#article/p_03003386. Accessed: 2019-02-20.

[9] SECO Tools. High Feed Mills. Available from: https://www.secotools.com/\#article/m_6904. Accessed: 2019-0315.

[10] Tsai, M-S.; Nien, H-W. \& Yau, H-T. (2009). Development of a real-time look-ahead interpolation methodology with spline-fitting technique for high-speed machining, Springer-Verlag London Limited 2009, In: International Journal of Advanced Manufacturing Technology (2010) vol. 47, pp. 621-638.

[11] Botko, F.; Hatala, M.; Duplák, J.; Olexa, I. \& Birčák J. (2018). Study of High Feed Cutting Efficiency of Aluminum Alloy AW - Alzn5,5mgcu. In: SAR Journal. Volume 1, Issue 2, Pages 53-56, ISSN 2619-9955, DOI: 10.18421/SAR12-04.

[12] Song, D.; Ma, J.; Jia, Z. \& Gao, Y. (2016). Estimation and compensation for continuous-path running trajectory error in high-feed-speed machining. In: International Journal of Advanced Manufacturing Technology (2017) vol. 89, pp. 1495-1508, DOI: 10.1007/s00170-016-9202-3.

[13] Duplák, J.; Hatala, M.; Dupláková, D. \& Steranka J. (2018). Evaluation of Time Efficiency of High Feed Milling. In: TEM Journal. Issue 7/2018, Pages 13-18, eISSN: 2217-8333.

[14] DMG MORI. HSC Machining with linear drives in all axes. Available from: https://cz.dmgmori.com/products/milling-machines/high-speed-precision-cutting-centres/hsc/hsc-105-linear. Accessed: 2019-04-10.

[15] SECO Tools. Catalogue and technical guide. Solid carbide end mills. 2015, 344 p.

[16] Material specification sheet - C45. Available from: https://www.saarstahl.com/sag/downloads/download/12970. Accessed: 2019-05-05.

[17] Zeiss. Shape Measuring Machine / Contour, Surfcom 5000, Carl Zeiss Industrielle Messtechnik Gmbh. Available from: http://www.directindustry.com/prod/carl-zeiss-industrielle-messtechnik-gmbh/product-5693-1071113.html. Accessed: 2019-06-01.

[18] Kuruc, M.; Vozár, M.; Šimna, V.; Vopát, T.; Hrušecký, R.; Milde, J.; Buranský, I.; Necpal, M. \& Peterka, J. (2018). Comparison of high feed machining with conventional milling in terms of dimensional accuracy and productivity, Proceedings of the 29th DAAAM International Symposium, Published by DAAAM International, Vienna, 2018, pages $426-434$. 